\title{
Results of Oncothermia Combined with Operation, Chemotherapy and Radiation Therapy for Primary, Recurrent and Metastatic Sarcoma
}

\author{
Tae Sig Jeung, Sun Young Ma, JiHoon Choi, Jeasang Yu, Su Yong Lee, Sangwook Lim \\ Department of Radiation Oncology, Kosin University College of Medicine, Busan, Korea \\ Email: tsjeung@daum.net
}

Received 2 April 2015; accepted 8 May 2015; published 13 May 2015

Copyright @ 2015 by authors and Scientific Research Publishing Inc.

This work is licensed under the Creative Commons Attribution International License (CC BY). http://creativecommons.org/licenses/by/4.0/

\section{(c) (i) Open Access}

\begin{abstract}
Sarcomas are relatively rare malignancies; however, their huge variety and shortage of the effective therapies make this disease face huge challenge for oncology. It is recently shown that hyperthermia could be successfully applied even in high-risk cases in combination with the available gold-standard regiments. Our aim is to present various advanced cases treated with a new hyperthermia method, oncothermia, showing its advantages and feasibility to successfully treat highly advanced sarcomas with curative intent.
\end{abstract}

\section{Keywords}

Hyperthermia, High-Risk, Sarcoma

\section{Introduction}

Sarcomas are tumors of putative mesenchymal origin. These malignancies are relatively rare; however, they are quite deadly, especially soft tissue sarcomas. The rarity of sarcomas combined with the diverse number of subtypes cause its study very difficult. Soft tissue sarcomas (STSs) are more common, $\sim 87 \%$ of all sarcoma cases are STSs, while only $\sim 13 \%$ were malignant bone tumors [1]. Despite its rare account, it is over $20 \%$ of all pediatric solid malignant tumors and less than $1 \%$ of all adult solid malignant cancers [1]. The two most common and distinct sarcoma groups are malignant bone and soft tissue neoplasms.

The risks factors for sarcoma are not well-understood, and can be divided into environmental exposures, genetic susceptibility, and their interactions [2]. The relatively common Kaposi’s sarcoma has origin from a virus, 
while the radiation exposure has been strongly associated with sarcoma development. Some secondary sarcomas believed to be caused by radiation therapy (RT). The risk of bone tumor grows in fact by cumulative dose of radiation. Sarcomas represent multiple malignancies rather than a single cancer [3], having more than 50 distinct histologic subtypes. Many sarcoma subtypes do not depend on age, and do not have any specific location of the body. The multidisciplinary approach to cancer care of sarcomas shows definite benefits in the diagnosis, treatment, and management of patients [4]. One has to avoid applying single technique and automatism in the treatment strategy [5]. Recently immune-therapy is emerging and seems promising [6]. The personalized medicine has to guide the therapy decisions [7].

The overall sarcoma incidence rates have increased slightly in the past 35 years. The 5-year relative survival rate for bone and soft tissue sarcoma is approximately $66 \%$ [8].

It seems that the primary reason for lethal danger of sarcomas is its difficult discovery, delayed diagnosis and advanced, mostly metastasis disease at presentation [8]. The pathophysiology, current and emerging therapies, and outcome for pediatric and young adult patients show a considerable diversity in cases of metastatic sarcoma [9]. There is no definitive chemotherapy regimen up to now to control effectively the sarcoma lesions. It is mostly resistant to radiotherapy too, because it has large portion of hypoxic cells. Mostly only surgery is the treatment possibility that shows definite response. However, the surgical solution also has complications due to a considerable proportion of patients with locally advanced tumors that cannot be resected with adequate clearance margins. Consequently, high incidence of local recurrence and distant metastases frequently occur after surgery. It is really not easy to decide which treatments are optimal for the actual cases [10]-[12]. The challenges are present in surgery [13], in chemotherapy [14], and in radiotherapy [15]. The immunotherapy promises some kind of solutions [6].

Hyperthermia is a good option to treat sarcoma cases because hypoxic cells are sensitive to heat. Furthermore, hyperthermia could increase the drug-intake by the higher blood-flow as well as at the same time the oxygenation to sensitize radiotherapy acts also. Its disadvantage is also connected to the increased blood-flow: the higher glucose delivery, increased glycolysis and the higher risk of invasion and dissemination of the malignant cells compete with actual advantages. The active chemo- or radio effects, however, could tilt the balance in favor of the cellular distortion before the survival advantages became effective. The application together with active chemotherapy [16] [17], or radiotherapy [18], or combined [19]-[21], shows remarkable successes. In combination with surgery, the effect is also promising even in high-grade sarcomas as well [22]-[24]. The hyperthermic isolated limb perfusion also shows promising approach [25] [26]. A remarkable prospective randomized doublearm multicenter clinical trial was recently published [27], showing impressive results both in local control and survival time. Not only the local but the systemic heating (whole-body hyperthermia WBH) also could be successfully applied with chemo-combination [28] [29]. The use of other hyperthermia modalities like high intensity focused ultrasound (HIFU) [30], and microwave induced hyperthermia [31] have also shown some promising results.

However, some drawbacks exist yet in hyperthermia applications [32]-[34]: the technical solutions are not effective enough to heat up the deep seated tumors; the development of the heat shock protein could lead to heat tolerance, and the uncontrolled blood-flow increase makes the treatment equivocal due to the intensive competition of the lethal heat effects and the supportive effects of the fresh blood-deliveries.

Oncothermia (OTM) is a new kind of hyperthermia [35], which makes nanoscopic heating selectively on the membrane of the malignant cells [36]. The important factor of the method is its intensive apoptotic action [37], which leads to the development of damaged associated molecular patterns (including the expression of TRAIL R2 (DR5) death receptor) [38], which promises new direction of immunotherapies by immunogenic cell-death. This approach could by-pass the problems with the classical heating, do it effectively on the selected local places. Our present goal is to show the feasibility of OTM treating various kinds of sarcomas. This work become important in parallel other sarcoma study with oncothermia [39].

\section{Methods and Materials}

13 sarcoma patients, 19 sites of local malignancy were treated with OTM from November 2011 to August 2013. Patients aged between 18 to 73 years old, the median was 48 years old. 6 male and 7 female patients were involved. Their histologic type contained soft-tissue sarcoma (STS) and bone related sarcomas. There were 2 rhabdomyosarcomas, 2 synovial sarcomas, 3 leiomyosarcomas, 1 malignant peripheral nerve sheath tumor, 1 
spindle sell sarcoma and 1 malignant fibrous histiocytoma (MFH), 2 chondrosarcomas, 1 osteosarcoma.

Treatment modality was 5 postoperative radiation therapies (RT) with OTM, 2 combined RT and OTM for primary lesion, 2 combined RT and OTM for recurrent sarcoma at original region and 4 combined RT and OTM for metastatic lesion. OTM was applied $2 \sim 3$ times a week, $3 \sim 108$ treatment sessions (median 18), at least one day off between the sessions. Post-operative RT was applied 50.4 Gy in 28 fractions and other RT was applied $30 \sim 39$ Gy in $10 \sim 13$ fractions. The combined chemotherapy with oncothermia for 1 case was applied to metastatic lung lesion, too.

\section{Results}

Five patients who received post-operative RT and oncothermia didn't show local recurrence. The metastatic lesion in lung appeared in 1 case and received chemotherapy, RT 50.4 Gy and 12 times of oncothermia and the metastatic lesion in lung almost completely regressed (CR). 1 (MFH) out of 2 patients for primary malignant lesion in pelvis received RT 50.4 Gy and 27 times of oncothermia and showed almost CR grossly at CT scan. However, this patient revealed local regrown mass in 6 months from stopping oncothermia. The other one (peripheral nerve sheath tumor) for primary lesion received RT 30 Gy in 2 weeks and 108 times of oncothermia for 11 months and tumor mass at buttock regressed continuously as repeated oncothermia. This patient is still getting oncothermia. 1 out of 2 recurrence rhabodomyosarcoma patients received RT 30 Gy in 2 weeks and 12 times of oncothermia in neck for 1 month. The tumor regressed partially. But metastatic lesion developed in retro-orbital region. RT 30 Gy in 10 fractions and 12 times of oncothermia for 1 month was given and metastatic mass of retro-orbital area also showed partial regression. Another patient (chondrosarcoma) had recurrence at pelvic bone replacement region after surgery. This patient received RT 30 Gy in 2 weeks and 50 times of oncothermia for 8 months and showed partial regression. It was thought to be difficult to apply oncothermia due to metallic pelvic bone replacement but she strongly requested receiving oncothermia. There were no side effects caused by metallic bone when oncothermia was applied. In 6 months follow-up tumor size did not increase in CT images from stopping oncothermia. For 4 patients the metastatic lesions were treated. 1 patient received RT 30 Gy in 2 weeks and 48 times of oncothermia for 7 months in metastatic lung lesion and showed grossly partial regression. After stopping the treatment, tumor mass was aggravated in size in 3 months, and 24 times of oncothermia was applied again and it was partially regressed. But after stopping treatment again, tumor regrew in 3 months and the patient received 11 oncothermia and tumor regressed but oncothermia was stopped due to patient's personal reason including economy. Other 1 patient (chondrosarcoma) had metastasis to chest wall and received RT 30 Gy in 10 fractions for 2 weeks and 47 times of oncothermia for 4.5 months and showed partial regression. It was stable for 4 months. One patient had cervical spine metastasis (spindle cell sarcoma) from right buttock and received RT 30 Gy in 2 weeks and 5 times of oncothermia. We found that oncothermia effectively controlled pain and made metastatic lesion stable. 1 patient (osteosarcoma) had multiple lung metastasis and received chemotherapy and 84 times of oncothermia for 12 months. Metastatic cancer almost disappeared but one lesion that was out of the range of $30 \mathrm{~cm}$ diameter electrode progressed. So the patient received radiotherapy (48 Gy in 4 fractions, SBRT) for the progressed lesion. Side effect of chemotherapy was not serious as much as we expected when oncothermia was combined with chemotherapy. Detailed case reports of some patients who were involved are described in details below.

\subsection{Patient \# 1}

The patient is a 70-year-old male. He has malignant peripheral nerve sheath tumor at buttock diagnosed in September 2012. He received radiotherapy 30 Gy in 10 fractions for 2 weeks in September 2012. Generally after the radiation therapy the tumor remained in progress for 2 months. Oncothermia was started 2 or 3 times a week complementary to radiotherapy. Tumor mass regressed after co-treatment of radiation therapy and oncothermia. Oncothermia was applied like the cancer would be chronic disease, keeping the patient alive as long as possible and keeping good quality of life. Tumor had regression by oncothermia treatment and this process was gradually continued when oncothermia was kept on for 1 year (Figure 1 ).

Now we are not able to decide when oncothermia should be stopped for this patient because he refuses any other treatments. He hopes to get oncothermia up to complete disappearance of tumor or until sign of regrowth appears. 


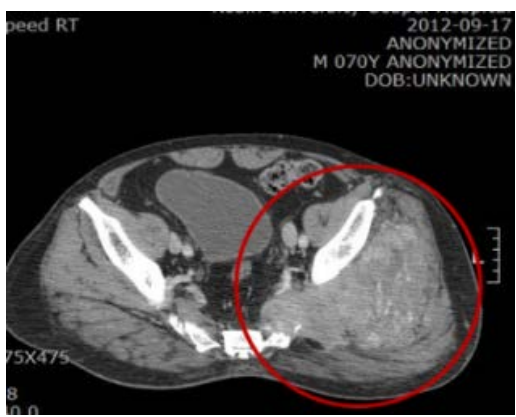

(a)

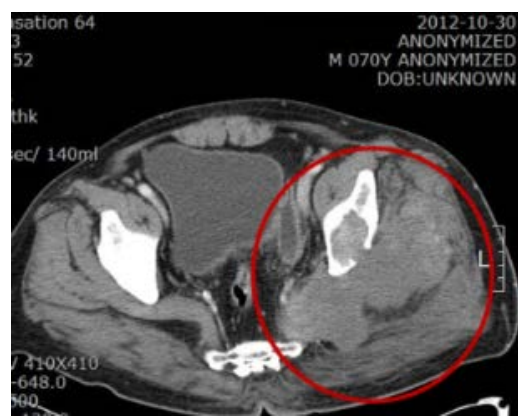

(b)

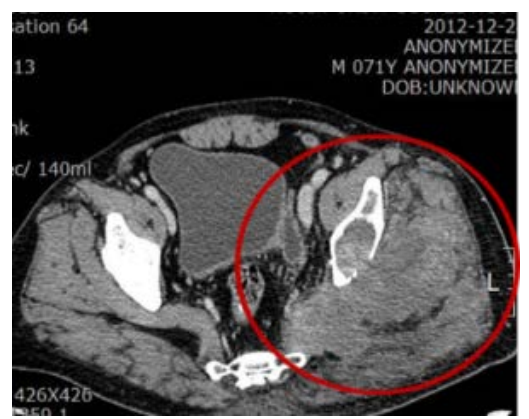

(c)

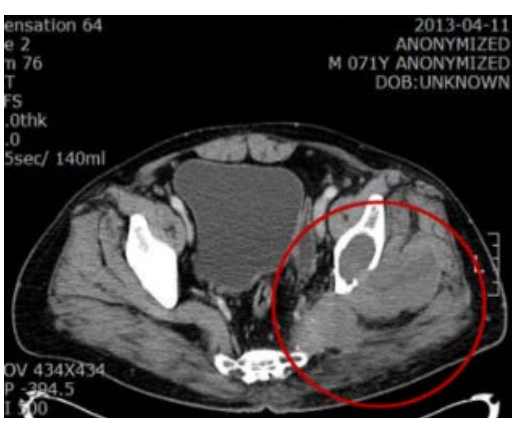

(d)

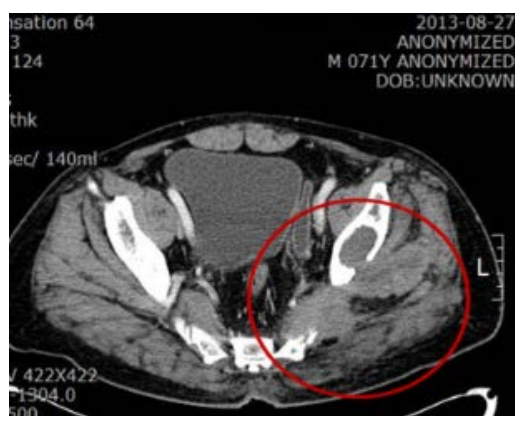

(e)

Figure 1. (a) Before RT-HT; (b) RT 30 Gy - HT 24\#; (c) RT 30 Gy - HT 48\#; (d) RT 30 Gy - HT 72\#; (e) RT 30 Gy - HT 108\# 1 year.

\subsection{Patient \#2}

This 24-year-old male was diagnosed with osteosarcoma of left femur. Operation was performed in June 2008, however, a lung metastasis was developed in 2009 and wedge resection of LUL/LLL in September 2010. A variety of chemotherapy regimens were given with wedge resection of tumor occasionally (ChemoTx: HD-MTx, AP, VIP, MTx/BCD, IA, IE $\rightarrow$ No more Tx). No more chemotherapy could be applied from July 2012 because of toxicity.

He received oncothermia treatment 82 times for 1 year from July 2012. Tumor masses under the applicator have regressed gradually with this treatment (Figure 2), but the lesion outside the treated volume remained in progress despite of the systemic chemotherapy (The RF electrode is $30 \mathrm{~cm}$ in diameter and is not able to include the whole lung in one treatment). This observation well showed that the effect was caused by oncothermia (Figure 3). Lesion outside of RF electrode progressed gradually.

\subsection{Patient \#3}

This 41-year-old female patient was diagnosed with leiomyosarcoma of uterus in January 2012. A total hysterectomy with both salping-oophorectomy was done.

Metastatic lesions at right external iliac node and both lungs were developed immediately after operation in February 2012. Chemotherapy (VIP regimen) and 48 times of oncothermia to pelvis and lung were given till March 2013. Metastatic cancer in pelvis was regressed almost completely. Radiation therapy 50.4 Gy in 28 fractions was given to prevent tumor regrowth in pelvis from January to February 2013 (Figure 4).

The oncothermia treated metastatic lung lesion revealed almost complete regression after finishing chemotherapy and 48 times of oncothermia. Lung lesions did not progress in 6 months from finishing oncothermia (Figure 5).

\subsection{Patient \#4}

This patient is a 57-year-old female. Diagnosis was synovial sarcoma of right thigh and operation was performed in November 2003. She lived well for 8 years with no evidence of disease, despite of loss of whole left 


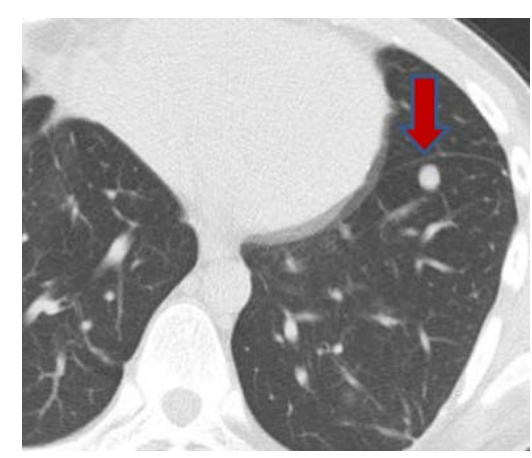

(a)

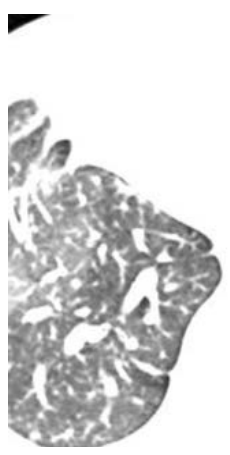

(b)

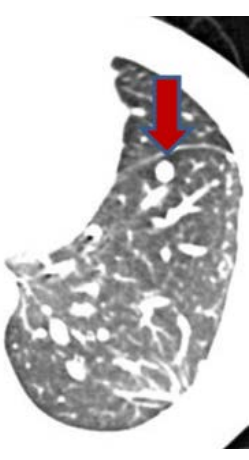

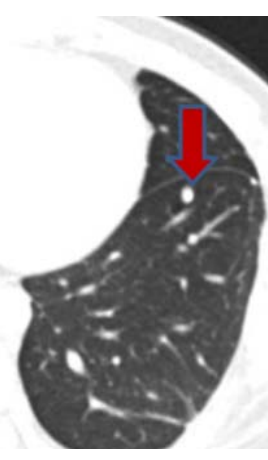

(c)

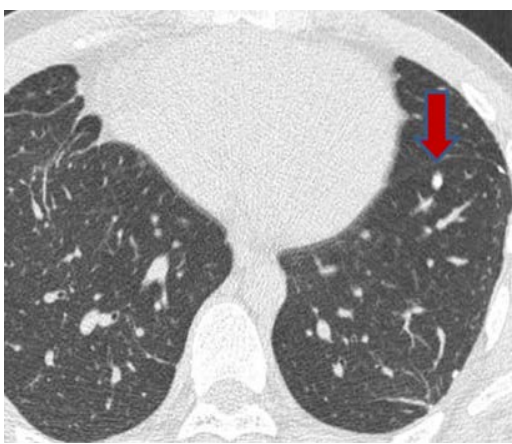

(d)

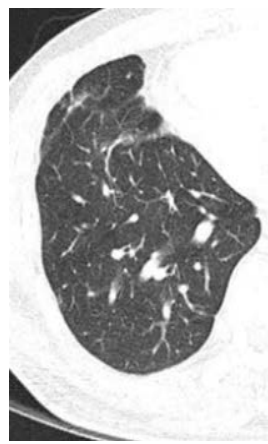

(e)

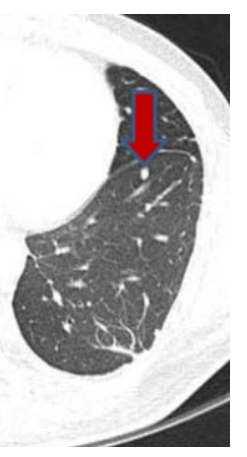

Figure 2. (a) Before ChemoTx-HT; (b) ChemoTx - HT 20\#; (c) ChemoTx - HT 40\#; (d) ChemoTx - HT 70\#; (e) ChemoTx - HT 82\# 1 year.

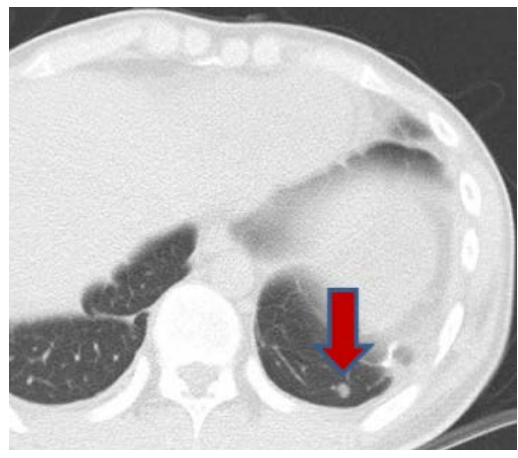

(a)

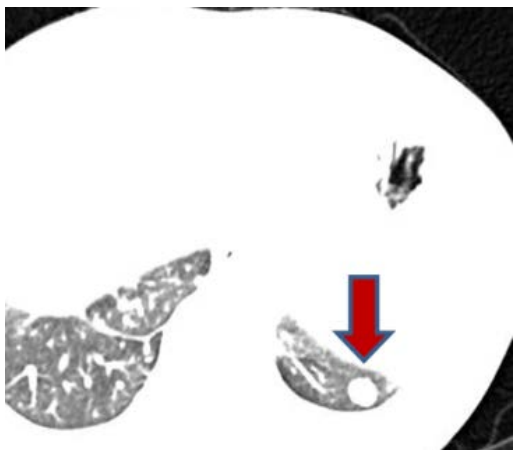

(b)

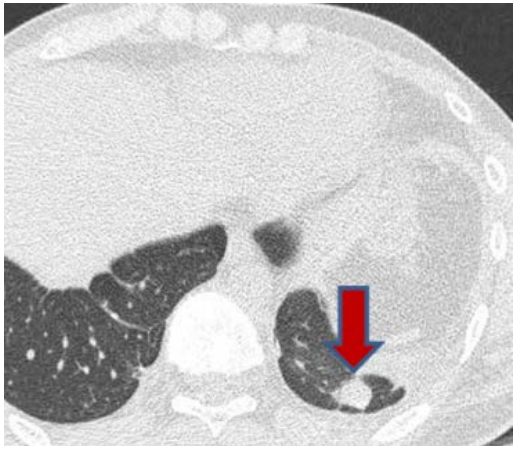

(c)

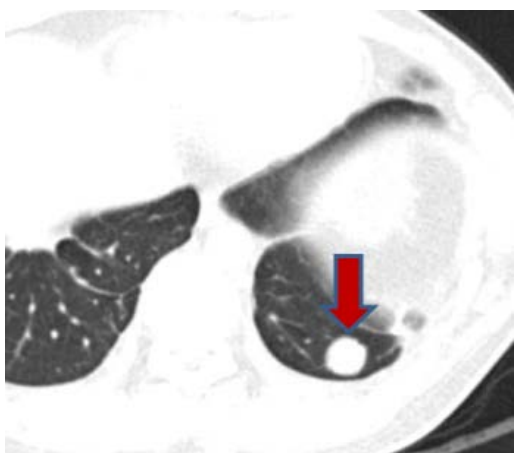

(d)

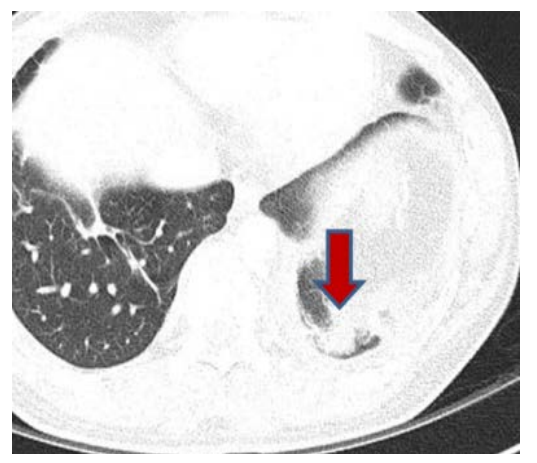

(e)

Figure 3. (a) Before ChemoTx-HT; (b) ChemoTx - HT 20\#; (c) ChemoTx - HT 40\#; (d) ChemoTx - HT 70\#; (e) ChemoTx - HT 82\# SBRT. 


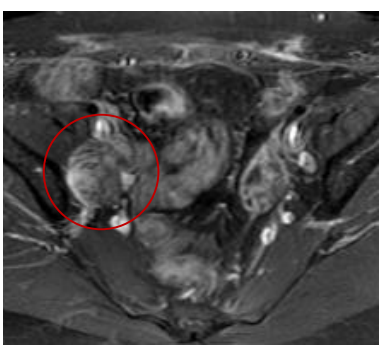

(a)

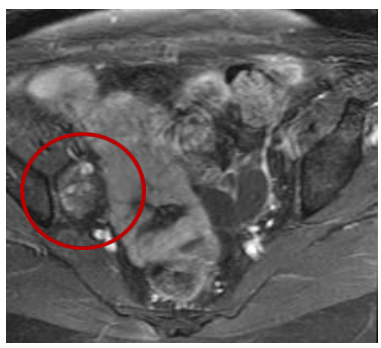

(b)

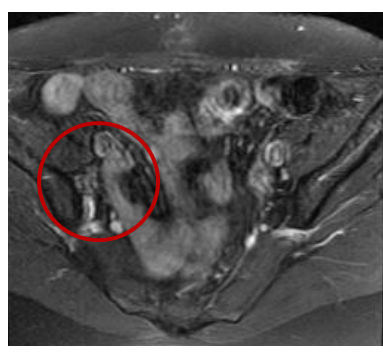

(c)

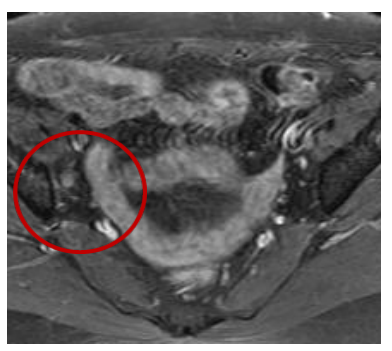

(d)

Figure 4. (a) Before Tx; (b) ChemoTx - HT 12\#; (c) ChemoTx - HT 36\#; (d) ChemoTx - HT 48\#.

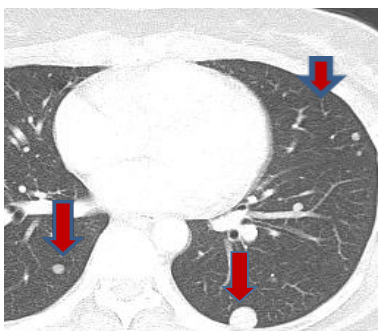

(a)

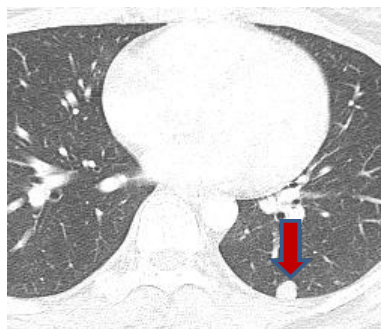

(b)

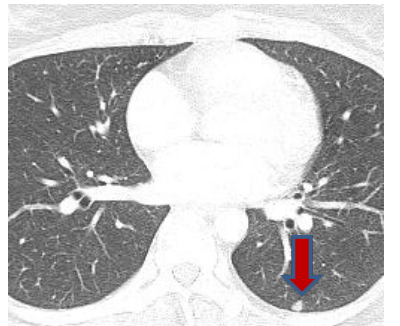

(c)

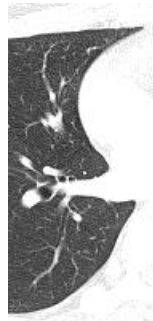

(d)

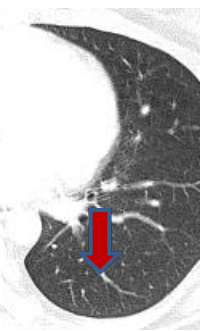

Figure 5. (a) Before ChemoTx and HT; (b) ChemoTx and HT 24\#; (c) ChemoTx and HT 48\#; (d) 6 months after ChemoTx and HT 48\#.

lobes of her lung by tuberculosis. However, metastatic cancer in the remained right lung was diagnosed in September 2011. She received radiation therapy 45 Gy in 15 fractions for 3 weeks with IGRT technique and it was followed by oncothermia 48 times. Tumor mass regressed with oncothermia. But tumor progressed again in 2 months from stopping oncothermia. 24 times of oncothermia were performed again and the tumor also regressed with oncothermia (Figure 6). Eventually tumor progressed since she gave up more oncothermia because of her poor economy.

\subsection{Patient \#5}

The 32-year-old male patient was diagnosed with malignant fibrous histiocytoma in left pelvis and sigmoidectomy \& partial cystectomy was performed in March 2012. Post-operative radiation therapy of 50.4 Gy in 28 fractions was given between April and June 2012, which was followed by oncothermia 27 times, good partial remission (almost complete) was achieved. Local recurrence was not known in a year from finishing oncothermia, but distant metastasis in lower abdominal wall appeared in more than one year after completing oncothermia in 2013. This other recurrent cancer on the left side of the abdominal wall grew rapidly (Figure 7).

\subsection{Patient \#6}

The 52-year-old female was diagnosed with chondrosarcoma at left iliac bone. Operation was performed in February 2006. She had pelvic metallic bone replacement at left iliac bone in 2010 when the lesion was recurrent. Recurrent cancer with bulky mass was noticed in June 2012. She requested oncothermia first but it was refused due to the pelvic metal. Only radiation therapy of $30 \mathrm{~Gy}$ in 10 fractions was given. But she forced to get oncothermia in spite of expecting serious complications after finishing radiation therapy. 36 times of oncothermia were given and tumor regressed prominently. Metal did not disturb oncothermia (Figure 8). But tumor progressed in 2 months from finishing oncothermia and aggravated much more in 5 months.

\subsection{Patient \#7}

Female patient diagnosed with chondrosarcoma at left iliac bone in February 2006 at the age of 52. Surgical intervention was applied immediately. She was re-operated at left iliac bone in 2010. Recurrent cancer and massive mass in size was observed in June 2012. She had re-irradiation 30 Gy and oncothermia but the cancer 


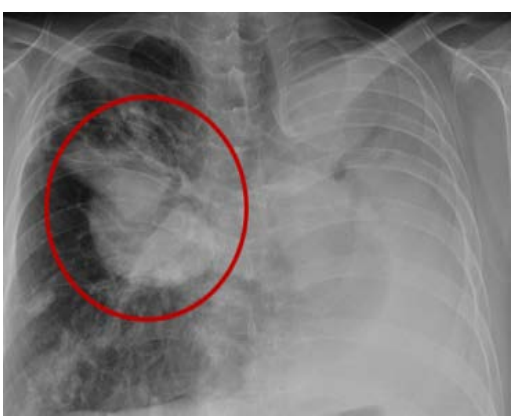

(a)

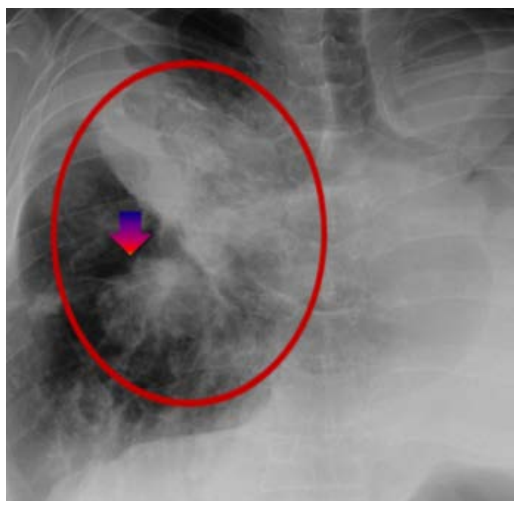

(d)

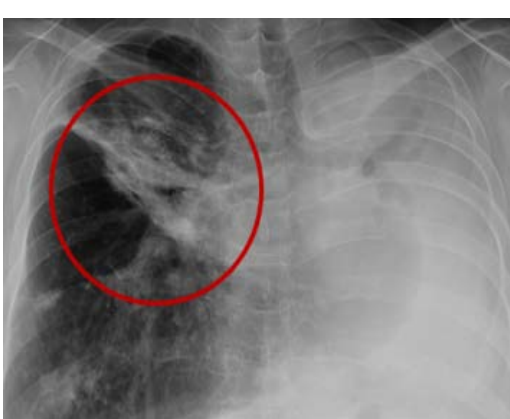

(b)

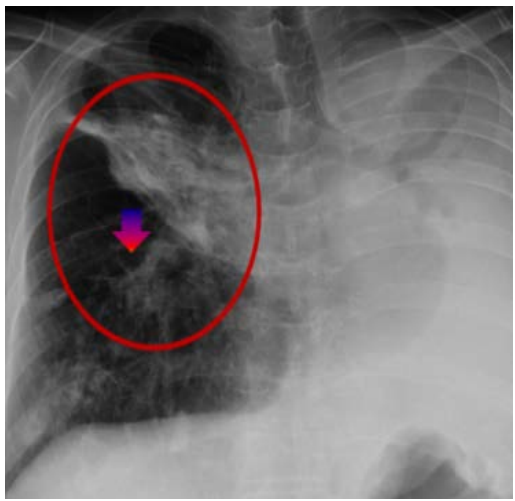

(e)

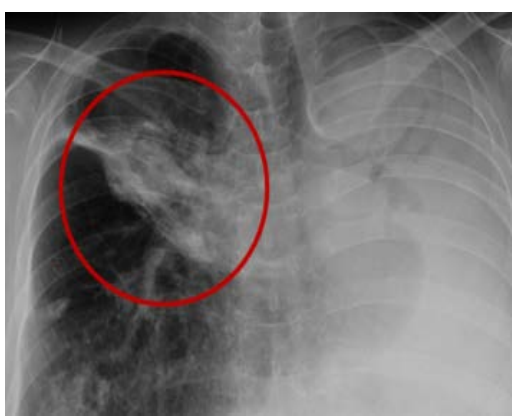

(c)

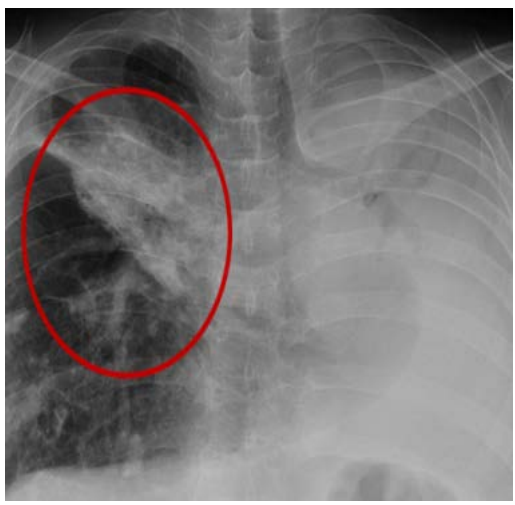

(f)

Figure 6. (a) Before RT - HT; (b) RT 45 Gy - HT 23\#; (c) RT 45 Gy - HT 48\#; (d) HT 48\# $\rightarrow 2$ Ms; (e) HT 48\# $\rightarrow 2$ Ms $\rightarrow$ HT 24\#; (f) HT 48\# $\rightarrow 2$ Ms $\rightarrow$ HT $24 \# \rightarrow 2$ Ms.

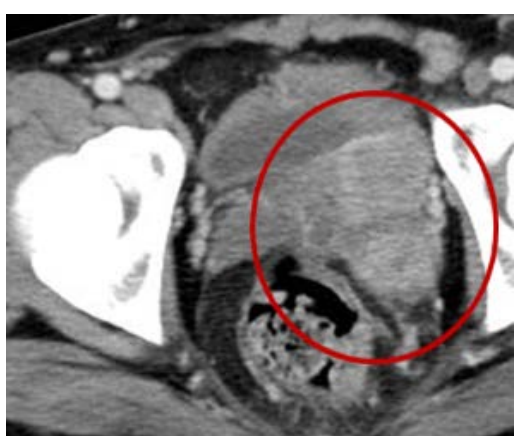

(a)

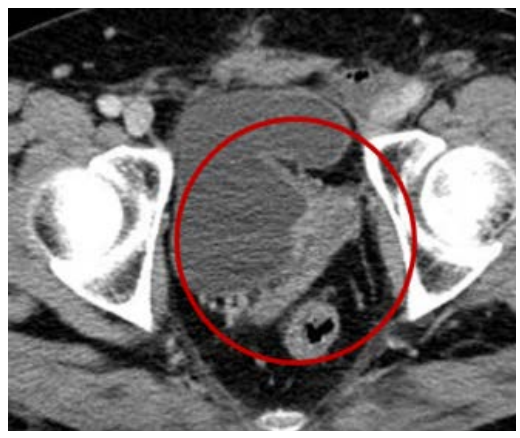

(d)

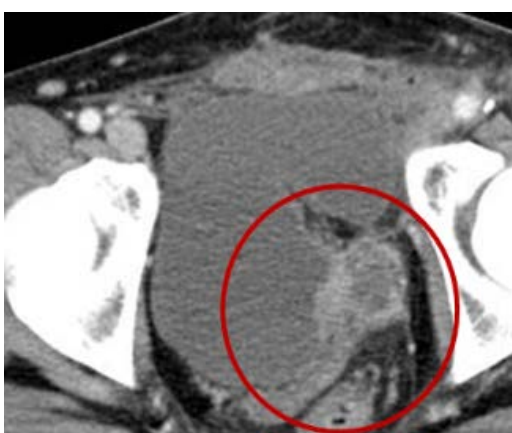

(b)

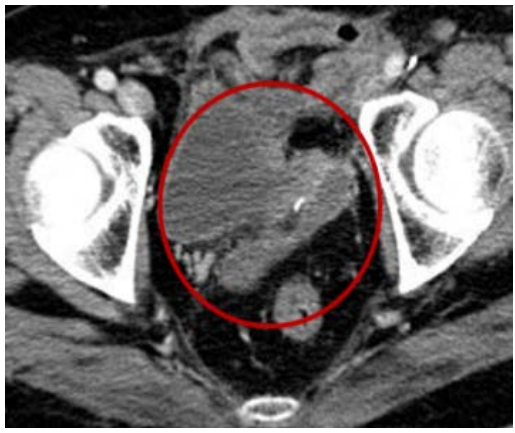

(e)

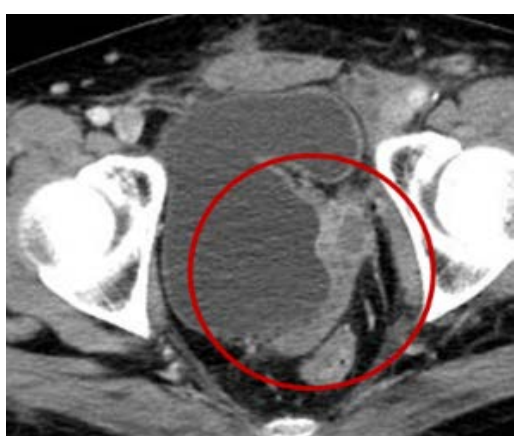

(c)

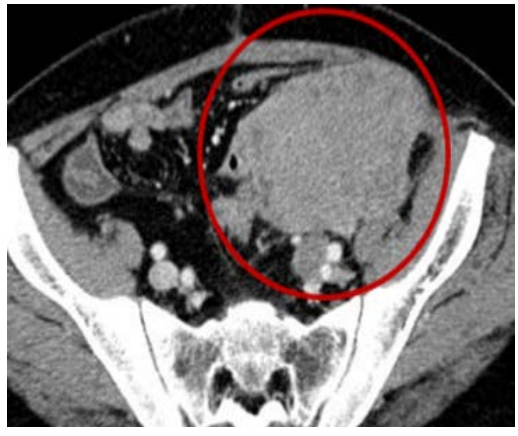

(f)

Figure 7. (a) Before OP; (b) Before Post-op, RT and HT; (c) RT50.4 Gy - HT 27\#; (d) RT and HT 27\# $\rightarrow 6$ Ms, e) RT and HT $27 \# \rightarrow 12 \mathrm{Ms}$, f) HT $27 \# \rightarrow 17$ Ms (1 and a half years) Mets to lower abd wall. 


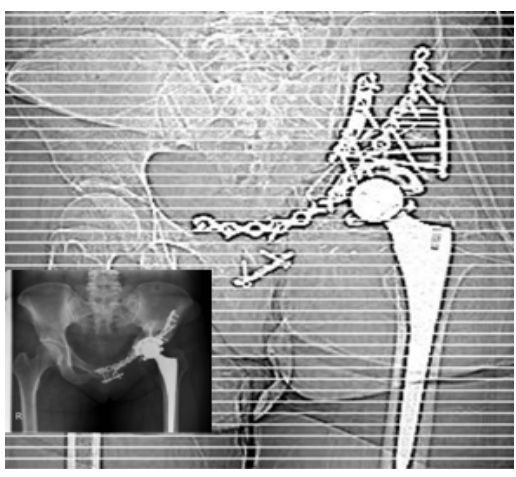

(a)

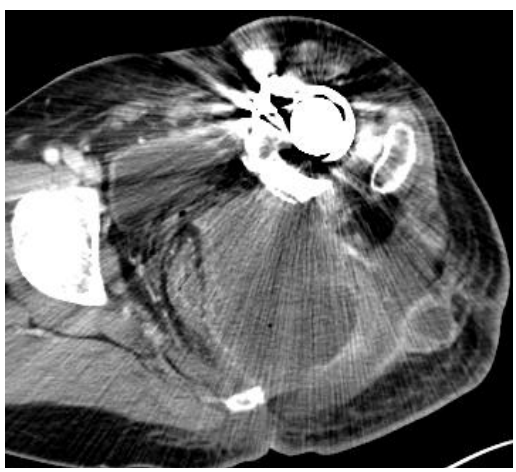

(d)

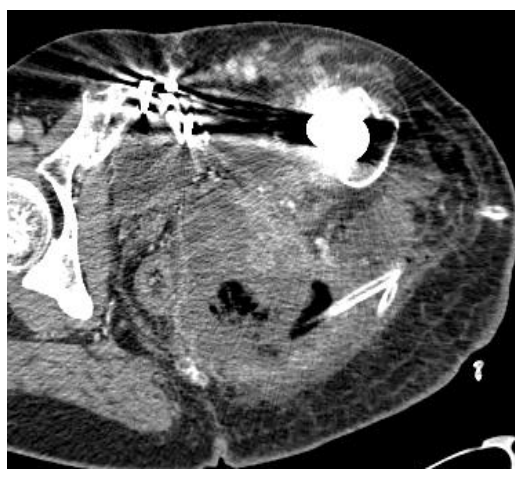

(b)

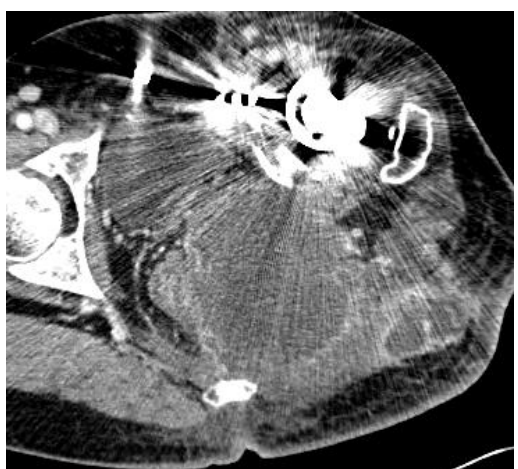

(e)

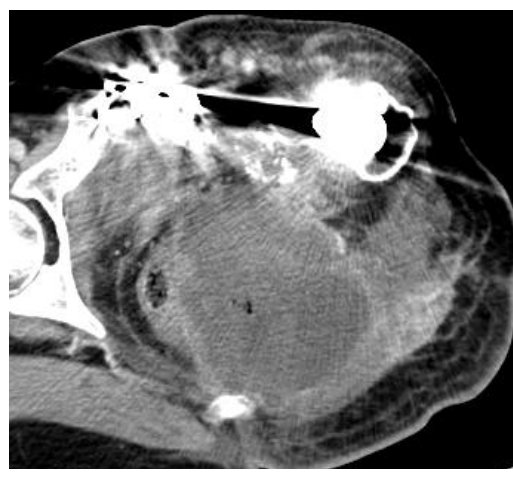

(c)

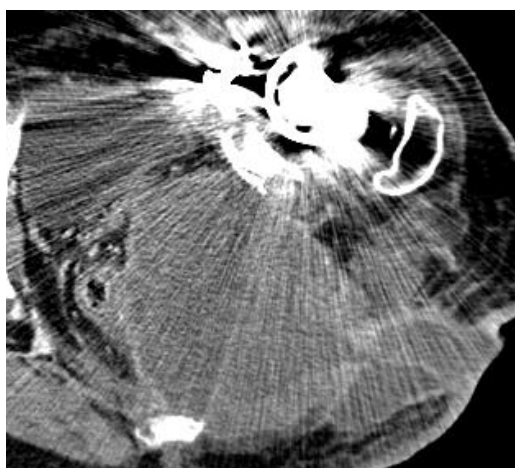

(f)

Figure 8. (a) Before RT and HT; (b) Before RT and HT; (c) RT 30 Gy and HT 12\#; (d) RT 30 Gy and HT 36\#; (e) RT 30 Gy and HT 36\# $\rightarrow 2$ Ms; (f) RT 30 Gy and HT 36\# $\rightarrow 5$ Ms.

regrew in 2 months from stopping the treatment. She received oncothermia 12 times again. The tumor kept on stable in 5 months after finishing re-irradiation and oncothermia (Figure 9).

\subsection{Patient \#8}

This 37-year-old male was diagnosed with chondrosarcoma of left hip. Surgical intervention was done in October 2003. Metastatic lesions were developed and lumpectomy of tumor was performed in April 2007. New bulky metastatic mass with massive pain was known at sternum in 2012. Sternal mass did not regress and pain was aggravated despite of $30 \mathrm{~Gy}$ of radiation therapy. Then oncothermia was applied 47 times. Anterior chest pain subsided immediately at a few times of oncothermia but sternal tumor mass did not regress fast but revealed stable or slightly regressed (Figure 10).

Metastatic lesions at both lower lungs enlarged in size. These lesions were not included in radio-frequency electrode field of oncothermia. Oncothermia was interrupted for 6 months because he had a traffic accident. He started to get radiation therapy and oncothermia to both lung lesions afterwards (Figure 11).

\subsection{Patient \# 9}

This 54-year-old female has got diagnosed as rhabdomyosarcoma at left infratemporal area in June 2011. Operation and post-operative radiation therapy of 50.4 Gy in 28 fractions were done from July to October 2011. Recurrent and metastatic cancer to left neck node developed in February 2013. Tumor mass regressed in response to 30 Gy radiation therapy and 12 times of oncothermia. But tumor progressed in 2 months after stopping oncothermia and progressed much more in 5 months (Figure 12).

Same patient developed massive metastatic cancer at left retro-orbital region with protruding orbit and massive pain in March 2013. This lesion also regressed in response to 30 Gy RT (2 25 April 2013) and 12 times of oncothermia (15 April 13 May 2013). But this lesion revealed progression on the CT scan in 6 months after finishing oncothermia, too (Figure 13). 


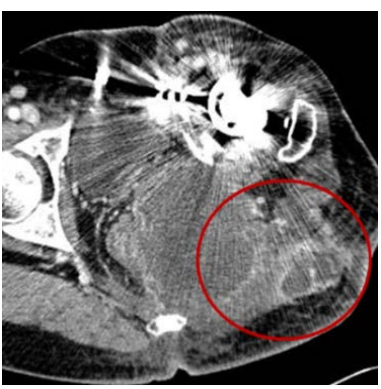

(a)

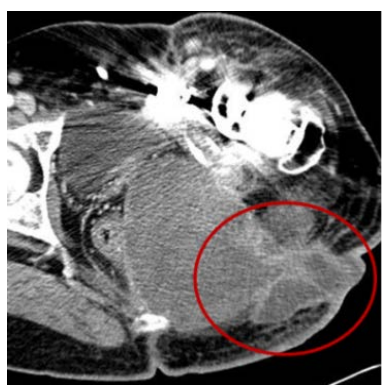

(b)

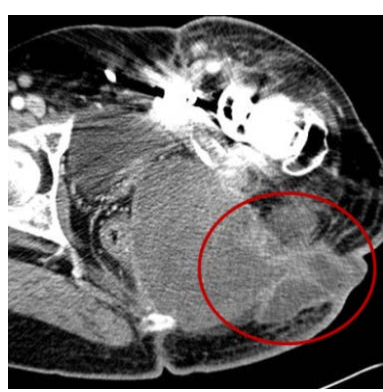

(c)

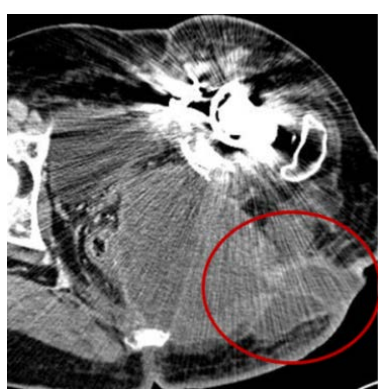

(d)

Figure 9. (a) RT 30 Gy and HT 36\# $\rightarrow 2$ Ms; (b) Re-RT 30 Gy and HT 12\#; (c) Re-RT 30 Gy and HT 12\# $\rightarrow 2$ Ms; (d) Re-RT 30 Gy and HT $12 \# \rightarrow 5$ Ms.

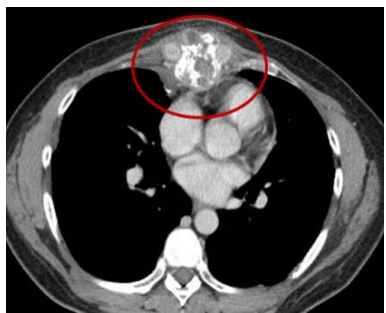

(a)

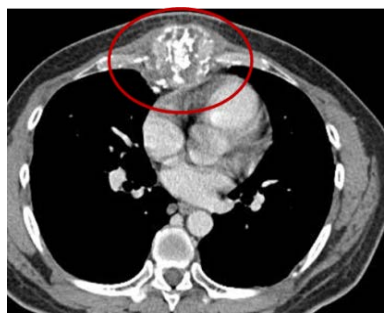

(b)

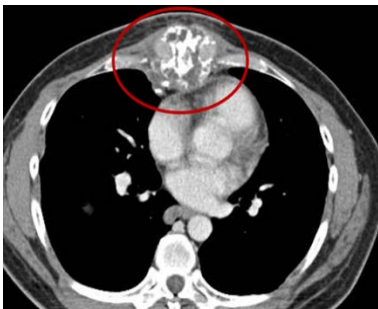

(c)

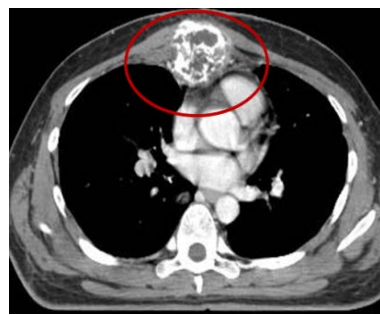

(d)

Figure 10. (a) Before HT and after RT 30 Gy; (b) HT 36\#; (c) 1 month from HT 47\#; (d) 5 months from HT 47\#.

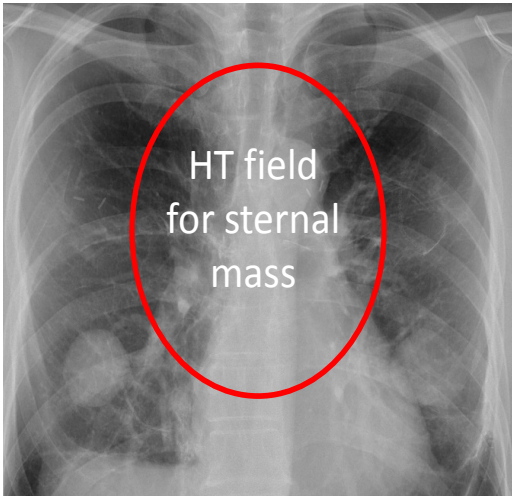

(a)

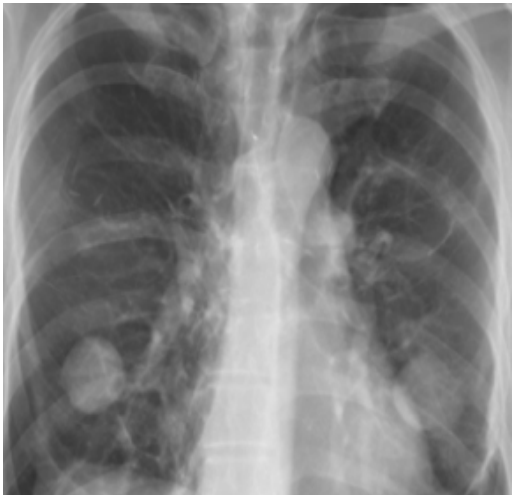

(b)

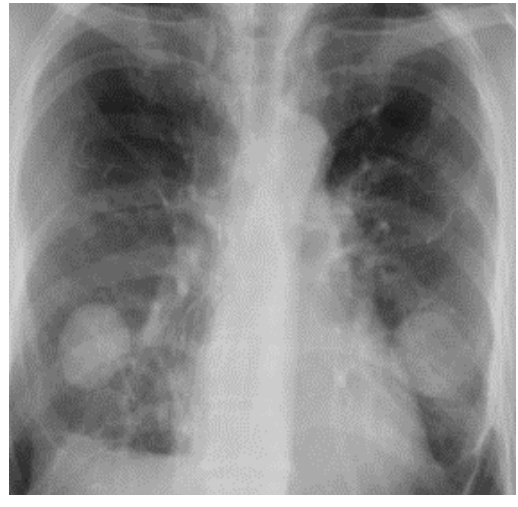

(c)

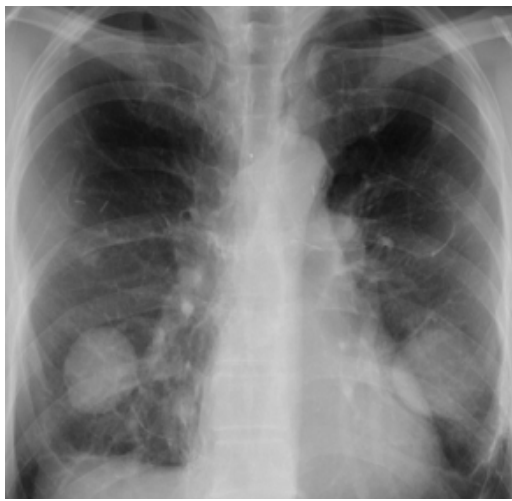

(d)

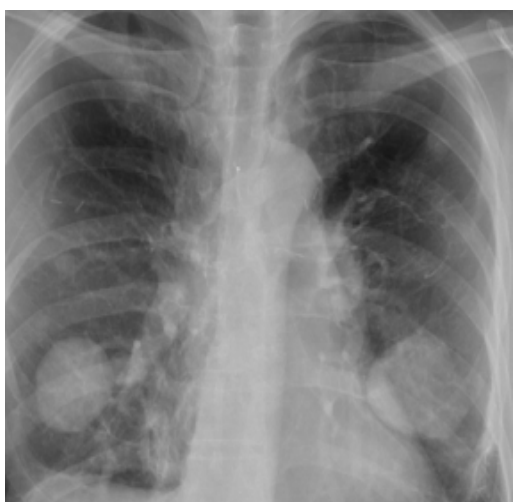

(e)

Figure 11. (a) 6 months before treatment; (b) Just before HT; (c) Just after HT 47\# for 5 Ms; (d) 3 months after HT 47\#, (e) 6 months after HT 47\#. 


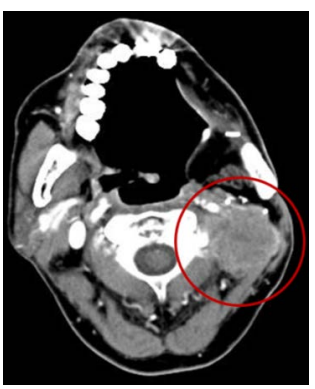

(a)

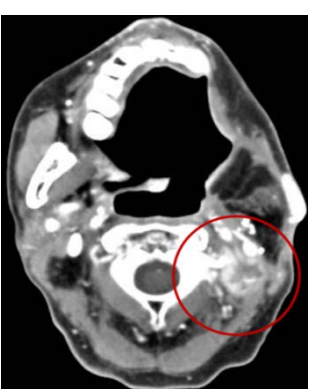

(b)

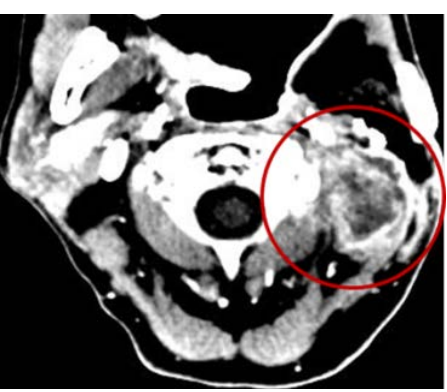

(c)

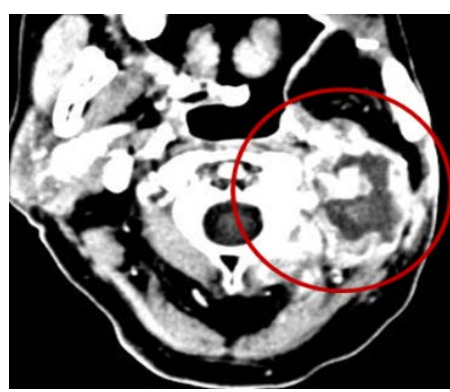

(d)

Figure 12. (a) Before RT and HT; (b) RT 30 Gy and HT 12\#; (c) RT 30 Gy and HT 12\# $\rightarrow 2$ Ms; (d) RT 30 Gy and HT $12 \# \rightarrow 5$ Ms.

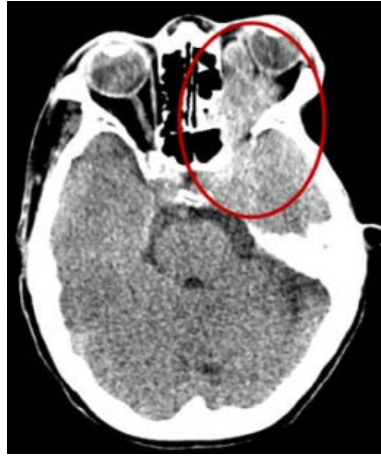

(a)

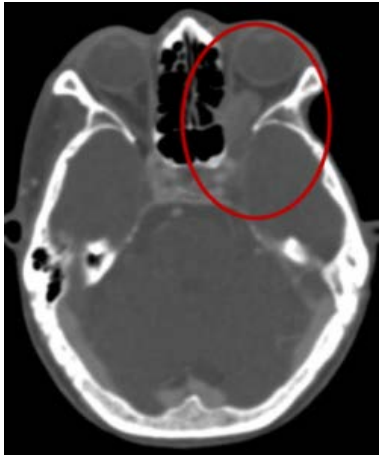

(b)

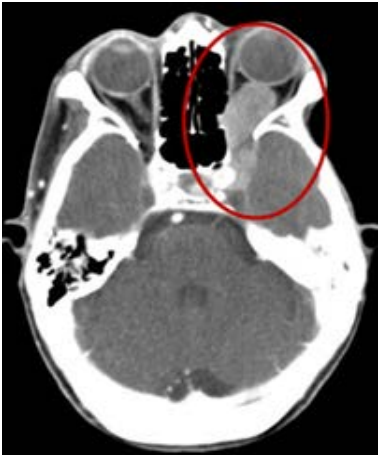

(c)

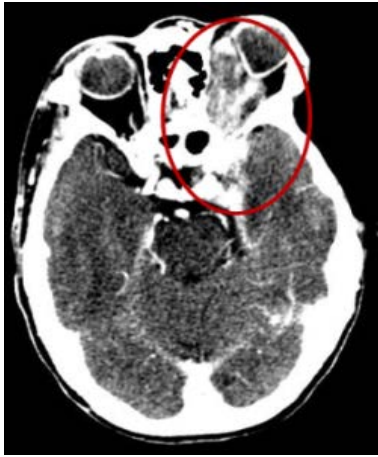

(d)

Figure 13. (a) Before RT and HT; (b) 1 Ms after RT 30 Gy and HT 12\#; (c) 4 Ms after RT 30 Gy and HT 12\#; (d) RT 30 Gy and HT $12 \# \rightarrow 6$ Ms.

\section{Discussion}

Efficacy of the combined OTM + RT therapy is proven by the results. 5 cases of post-operative RT and OTM revealed no local recurrence but 1 lung metastasis developed. In 2 cases complete remission (CR) was observed, with chemotherapy and/or RT, in 3 cases stable response, in 5 cases pain relieved effectively, all other combined oncothermia with RT and/or chemotherapy represented partial response (9/12).

- Primary, recurrent, and metastatic sarcomas responded to oncothermia and it was more effective with combined RT and/or chemoTx.

- Tumor regressed slowly without thermo-tolerance when oncothermia was applied for long term.

- Pain control: highly effective for metastatic bone tumors.

- Important observation: oncothermia effect is proven in the technically not treatable lesion that was growing despite the concomitant systemic chemo-therapy, while the other lesion regressed at the same time.

- The long-time care is also remarkable which makes the lethal disease chronic (like dialysis does). The strong correlation between the oncothermia treatment and the tumor-regression is shown by the termination and re-application of the treatment.

\section{Conclusion}

Primary, recurrent, and metastatic sarcomas responded to oncothermia treatment and the mass regressed. When oncothermia was applied for long term, tumor mass regressed slowly for oncothermia. It is needed to study further to see that complete regression can be achieved with oncothermia only and to increase effects with the combined modalities of oncothermia with chemotherapy and/or radiation therapy.

\section{References}

[1] Surveillance, Epidemiology, and End Results (SEER) Research Data, Nov 2010 Sub (1973-2008) Total U.S., 1969- 
2009. National Cancer Institute, Surveillance Research Program, Cancer Statistics Branch, Released April 2011, Based on the November 2010 Submission. http://seer.cancer.gov/

[2] Fletcher, C.D.M., Krishnan, U.K. and Mertens, F. (2002) World Health Organization Classification of Tumours: Pathology and Genetics of Tumours of Soft Tissue and Bone. IRAC Press, Lyon, 298.

[3] Lahat, G., Lazar, A. and Lev, D. (2008) Sarcoma Epidemiology and Etiology: Potential Environmental and Genetic Factors. Surgical Clinics, 88, 451-481. http://dx.doi.org/10.1016/j.suc.2008.03.006

[4] Cheong, D., Gonzalez, R.J. and Zager, J.S. (2011) Strategies for Solutions in Sarcoma Management. Cancer Control, 18, 148-149.

[5] Riddle. N.D., Gonzalez, R.J., Bridge, J.A., Antonia, S. and Bui, M.M. (2011) A CD117 and CD34 Immunoreactive Sarcoma Masquerading as a Gastrointestinal Stromal Tumor: Diagnostic Pitfalls of Ancillary Studies of Sarcoma. Cancer Control, 18, 152-159.

[6] D’Angelo, S.P., Tap, W.D., Schwartz, G.K. and Carvajal, R.D. (2014) Sarcoma Immunotherapy: Past Approaches and Future Directions. Sarcoma, 2014, Article ID: 391967. http://dx.doi.org/10.1155/2014/391967

[7] Reed, D. and Altiok, S. (2011) Metastatic Soft Tissue Sarcoma Cemeotherapy: An Opportunity for Personalized Medicine. Cancer Control, 18, 188-195.

[8] National Cancer Institute (2010) Snapshots of Specific Types of Cancer. National Cancer Institute. http://www.cancer.gov/aboutnci/servingpeople/cancer-statistics/snapshots

[9] Amankwah, E.K., Conley, A.P. and Reed, D.R. (2013) Epidemiology and Therapies for Metastatic Sarcoma. Clinical Epidemiology, 5, 147-162.

[10] Hohenberger, P. and Wysocki, W.M. (2008) Neoadjuvant Treatment of Locally Advanced Soft Tissue Sarcoma of the Limbs: Which Treatment to Choose? The Oncologist, 13, 175-186. http://dx.doi.org/10.1634/theoncologist.2007-0165

[11] Amankwah, E.K., Conley, A.P. and Reed, D.R. (2013) Epidemiology and Therapies for Metastatic Sarcoma. Clinical Epidemiology, 5, 147-162.

[12] Banerjee, R., Bandopadhyay, D. and Abilash, V.G. (2013) Epidemiology, Pathology, Types and Diagnosis of Soft Tissue Sarcoma: A Research Review. Asian Journal of Pharmaceutical and Clinical Research, 6, 18-25.

[13] Marulanda, G.A., Henderson, E.R., Johnson, D.A., Letson, G.D. and Cheong, D. (2008) Orthopedic Surgery Options for the Treatment of Primary Osteosarcoma. Cancer Control, 15, 13-20.

[14] Marulanda, G.A. and Letson, G.D. (2014) Controversies in Sarcoma. http://sarcomahelp.org/articles/controversies.html

[15] Esler, C.P. and Ashford, R.U. (2013) Radiotherapy Controversies in the Radical Treatment of Soft-Tissue Sarcomas of the Limb. European Oncology \& Haematology, 9, 42-45.

[16] Fiegl, M., Schlemmer, M., Wndtner, C.M., Abdel-Rahman, S., Fahn, W. and Issels, R.D. (2004) Isofamide, Carboplatin and Etoposide (ICE) as Second-Line Regimen Alone and in Combination with Regional Hyperthermia Is Active in Chemo-Pre-Treated Advanced Soft Tissue Sarcoma of Adults. International Journal of Hyperthermia, 20, 661-670. http://dx.doi.org/10.1080/02656730410001714959

[17] Doi, O., Kodama, K., Tatsuta, M., Higashiyama, M., Aoki, Y., Kuriyama, K., et al. (1990) Effectiveness of Intrathoracic Chemothermotherapy for Malignant Pleurisy Due to Ewing's Sarcoma: A Case Report. International Journal of Hyperthermia, 6, 963-969. http://dx.doi.org/10.3109/02656739009140979

[18] Hiraoka, M., Nishimura, Y., Nagata, Y., Mitsumori, M., Okuno, Y., Li, P.Y., et al. (1995) Clinical Results of Thermoradiotherapy for Soft Tissue Tumors. International Journal of Hyperthermia, 11, 365-377. http://dx.doi.org/10.3109/02656739509022472

[19] Egawa, S., Tsukiyama, I., Kajiura, Y., et al. (1993) Clinical Results of Hyperthermia Combined with Radiation or Chemotherapy for Soft-Tissue Sarcomas. In: Matsuda, T., Ed., Cancer Treatment by Hyperthermia, Radiation and Drugs, Taylor and Francis, London, 290-299.

[20] Otsuka, T., Yonezawa, M., Kamiyama, F., Matsushita, Y. and Matsui, N. (2001) Results of Surgery and Radio-HyperThermo-Chemotherapy for Patients with Soft-Tissue Sarcoma. International Journal of Clinical Oncology, 6, 253-258. http://dx.doi.org/10.1007/PL00012114

[21] Leopold, K. and Issels, R.D. (2012) Thermoradiotherapy and Thermochemotherapy for Sarcomas. In: Seegenschmiedt, M.H., Fessenden, P. and Vernon, C.C., Eds., Thermo-Radiotherapy and Thermo-Chemotherapy, Vol. 2, Clinical Applications, Springer, Berlin, 147-158.

[22] Prosnitz, L.R., Maguire, P., Anderson, J.M., Scully, S.P., Harrelson, J.M., Jones, E.L., et al. (1999) The Treatment of High-Grade Soft Tissue Sarcomas with Preoperative Thermoradiotherapy. International Journal of Radiation Oncology*Biology*Physics, 45, 941-949. http://dx.doi.org/10.1016/S0360-3016(99)00272-2

[23] Issels, R.D., Bosse, D., Abdel-Rahman, S., Starck, M., Panzer, M., Jauch, K.W., et al. (1993) Preoperative Systemic Etioposide/Ifosfamide/Dox-Orubicin Chemotherapy Combined with Regional Hyperthermia in High-Risk Sarcoma: A 
Pilot Study. Cancer Chemotherapy and Pharmacology, 31, S233-S237.

[24] Issels, R.D., Abdel-Rahman, S., Wendtner, C.M., Falk, M.H., Kurze, V., Sauer, H., et al. (2001) Neoadjuvant Chemotherapy Combined with Regional Hyperhtermia (RHT) for Locally Advanced Primary or Recurrent High-Risk Adult Soft-Tissue Sarcomas (STS) of Adults: Long-Term Results of a Phase II Study. European Journal of Cancer, 37, 1599-1608. http://dx.doi.org/10.1016/S0959-8049(01)00183-6

[25] Schraffordt, K.H., Eggermont, A.M., Lienard, D., Kroon, B.B.R., Hoekstra, H.J., et al. (1998) Hyperthermic Isolated Limb Perfusion for the Treatment of Soft Tissue Sarcomas. Seminars in Surgical Oncology, 14, 210-214. http://dx.doi.org/10.1002/(SICI)1098-2388(199804/05)14:3<210::AID-SSU4>3.0.CO;2-B

[26] Kim, C.J., Puleo, C., Letson, G.D. and Reintgen, D. (2001) Hyperthermic Isolated Limb Perfusion for Extremity Sarcomas. Cancer Control: Journal of the Moffitt Cancer Center, 8, 269-273.

[27] Issels, R.D., Lindner, L.H., Verweij, J., Wust, P., Reichardt, P., Schem, B.-C., et al. (2010) Neo-Adjuvant Chemotherapy Alone or with Regional Hyperthermia for Localised High-Risk Soft-Tissue Sarcoma: A Randomised Phase 3 Multicentre Study. The Lancet Oncology, 11, 561-570. http://dx.doi.org/10.1016/S1470-2045(10)70071-1

[28] Wiedemann, G.J., Robins, H.I., Katschinski, D.M., Mentzel, M., D’Oleire, F., Kutz, M., et al. (1997) Systemic Hyperthermia and ICE Chemotherapy for Sarcoma Patients: Rationale and Clinical Status. Anticancer Research, 17, 2899-2902.

[29] Wiedemann, G.J., d’Oleire, F., Knop, E., Eleftheriadis, S., Bucsky, P., Feddersen, S., et al. (1994) Ifosfamide and Carboplatin Combined with 41.8 Degrees C Whole-Body Hyperthermia in Patients with Refractory Sarcoma and Malignant Teratoma. Cancer Research, 54, 5346-5350.

[30] Chen, W., Zhu, H., Zhang, L., Li, K.Q., Su, H.B., Jin, C.B., et al. (2010) Primary Bone Malignancy: Effective Treatmentwith High-Intensity Focused Ultrasound Ablation. Radiology, 255, 967-978. http://dx.doi.org/10.1148/radiol.10090374

[31] Hu, Y.C., Ji, J.T. and Lun, D.X. (2011) Intraoperative Microwave Inactivation In-Situ of Malignant Tumors in the Scapula. Orthopaedic Surgery, 4, 229-235. http://dx.doi.org/10.1111/j.1757-7861.2011.00149.x

[32] Szasz, A. (2013) “Quo Vadis” Oncologic Hyperthermia? Conference Papers in Medicine, 2013, Article ID: 201671.

[33] Roussakow, S. (2013) The History of Hyperthermia Rise and Decline. Conference Papers in Medicine, 2013, Article ID: 428027.

[34] Baronzio, G., Jackson, M., Lee, D. and Szasz, A. (2013) Editorial of the Conference of the International Clinical Hyperthermia Society 2012. Conference Papers in Medicine, 2013, Article ID: 690739.

[35] Szasz, A., Szasz, N. and Szasz, O. (2010) Oncothermia: Principles and Practices. Springer, Dordrecht, Heidelberg.

[36] Szasz, O. and Szasz, A. (2014) Oncothermia-Nano-Heating Paradigm. Journal of Cancer Science \& Therapy, 6, 117121. http://omicsonline.org/open-access/oncothermia-nanoheating-paradigm-1948-5956.1000259.pdf

[37] Meggyeshazi, N., Andocs, G., Balogh, L., Balla, P., Kiszner, G., Teleki, I., et al. (2014) DNA Fragmentation and Caspase-Independent Programmed Cell Death by Modulated Electrohyperthermia. Strahlentherapie und Onkologie, 190, 815-822. http://dx.doi.org/10.1007/s00066-014-0617-1

[38] Andocs, G., Meggyeshazi, N., Balogh, L., Spisak, S., Maros, M.E., Balla, P., et al. (2014) Upregulation of Heat Shock Proteins and the Promotion of Damage-Associated Molecular Pattern Signals in a Colorectal Cancer Model by Modulated Electrohyperthermia. Cell Stress and Chaperones, 20, 37-46. http://dx.doi.org/10.1007/s12192-014-0523-6

[39] Volovat, S.R., Volovat, C., Scripcariu, V., Lupascu, C. and Miron, L. (2014) The Results of Combination of Ifosfamid and Locoregional Hyperthermia (EHY 2000) in Patients with advanced Abdominal Soft-Tissue Sarcoma after Relapse of First Line Chemotherapy. Romanian Reports in Physics, 66, 175-181. 